\title{
Seismic Analysis of a Reinforced Concrete Building by Response Spectrum Method
}

\author{
A. E. Hassaballa ${ }^{1}$, Fathelrahman M. Adam. ${ }^{2}$, M. A. Ismaeil ${ }^{3}$ \\ 1. Department of Civil Engineering, Jazan University, Jazan, KSA \\ 2. Department of Civil Engineering, Jazan University, Jazan, KSA \\ 3. King Khalid University, KSA. On Leave from Sudan University of Science and Technology, Khartoum, Sudan
}

\begin{abstract}
Seismic analysis of a multi-story RC frame in Khartoum city was analyzed under moderate earthquake loads as an application of seismic hazard, and in accordance with the seismic provisions proposed for Sudan[1]to investigate the performance of existing buildings if exposed to seismic loads. The frame was analyzed using the response spectrum method to calculate the seismic displacements and stresses. The results obtained, clearly, showthat the nodal displacements caused drifts in excess of approximately 2 to 3 times the allowable drifts. The horizontal motion has a greater effect on the axial compression loads of the exterior columns compared to the interior columns andthe compressive stresses in ground floor columns were about 1.2 to 2 times the tensile stresses. The values of shear forces due to L/C3 in beams B805, B806 and B807 were found to be about four times the values due to $\mathrm{L} / \mathrm{C} 1$. The maximum values of compressive and tensile stresses in beams are approximately equal. Bending moments in beams and columns due to seismic excitation showed much larger values compared to that due to static loads.
\end{abstract}

Keywords: - Displacements, Drifts, Seismic Analysis, Seismic Hazard,Stresses, Sudan

\section{INTRODUCTION}

Earthquakes, caused by movements on the earth surface, result in different levels of ground shaking leading to damage and collapse of buildings and civil infra-structures, landslides in the case of loose slopes, and liquefaction of sandy soil [2]. Thebehavior of reinforced concrete moment resisting frame structures in recent earthquakes all over the world has highlighted the consequences of poor performance of beam column joints [3]. Beam column joints in a reinforced concrete moment resisting frame are crucial zones for transfer of loads effectively between the connecting elements (i.e., beams and columns) in the structures [3]. Traditionally, seismic design approaches are stated, as the structure should be able to ensure the minor and frequent shaking intensity without sustaining any damage, thus leaving the structure serviceable after the event [4].The structure should withstand moderate level of earthquake ground motion without structural damage, but possibly with some structural as well as non-structural damage. This limit state may correspond to earthquakeintensity equal to the strongest either experienced or forecast at the site. The results are studied for responsespectrum method. The main aim of this paper is to investigate the seismic performance of a reinforced concrete moment resisting frame building under a moderate earthquake ground motion. The building, which is located in Khartoum City (zone 2), was analyzed in accordance with the suggested seismic provisions proposed for Sudan [1].

\section{RESPONSE SPECTRUM METHMOD}

The response spectrum represents an envelope of upper bound responses, based on several different ground motion records. This methodis an elastic dynamic analysis approach that relies on the assumption that dynamic response of the structure maybe found by considering the independent response of each natural mode of vibration and then combining theresponse of each in same way. This is advantageous in the fact that generally only few of the lowest modes ofvibration have significance while calculating moments, shear and deflections at different levels of the building.

Following procedure is generally used for the spectrum analysis [2]:

[1] Select the design spectrum.

[2] Determine the mode shapes and periods of vibration to be included in the analysis.

[3] Read the level of response from the spectrum for the period of each of the modes considered

[4] Calculate participation of each mode corresponding to the single-degree-of-freedom response read from the curve.

[5] Add the effect of modes to obtain combined maximum response.

[6] Convert the combined maximum response into shears and moments for use in design of the structure. 


\section{RESPONSE SPECTRUM METHMOD BY USING STAADPRO}

This is accurate method of analysis. The design lateral force at each floor in each mode is computed by STAADPro [5]. The software provides results for design values, modal masses and storey base shear. STAAD utilizes the following procedure to generate the lateral seismic loads.

[1] Program calculates time periods for first six modes or as specified by the user.

[2] Program calculates $\mathrm{Sa} / \mathrm{g}$ for each mode utilizing time period and damping for each mode.

[3] The program calculates design horizontal acceleration spectrum Ak for different modes.

[4] The program then calculates mode participation factor for different modes.

[5] The peak lateral seismic force at each floor in each mode is calculated.

[6] All response quantities for each mode are calculated.

[7] The peak response quantities are then combined as per method (CQC or SRSS or ABS or TEN or CSM) as defined by the user to get the final results.

\section{LOAD COMBINATION}

In designing for seismic forces, the following two combinations can be considered [1]:

$A=D+L \cdot p+E$

$A=0.85 D+E$

Where

$\mathrm{D}=$ dead load;

$\mathrm{L}=$ live load;

$\mathrm{P}=$ incidence factor for live load; and

$\mathrm{E}=$ earthquake load.

\section{FRAME DETAILS AND STUDY CASE}

A traditional residential ten-storey regular reinforced concrete frame building located in Khartoum City, with $12 \mathrm{~m} \times 20 \mathrm{~m}$ plan as shown in Fig. 1, was analyzed to investigate its seismic performance. The most important parameters governing the analysis of this frame were dead load, live load and seismic loads. Seismic loads were computed based on the Response Spectrum Approach (RSA). Three combinations of load cases were applied as follows:

Load Case $1(\mathrm{~L} / \mathrm{C} 1)$ is static load (dead and live) are follow the rules given in the (BS 8110, 1997) [6].

Load Case $2(\mathrm{~L} / \mathrm{C} 2)$ is seismic loads.

Load Case $3(\mathrm{~L} / \mathrm{C} 3)$ is (static + seismic) loads.

A uniformly distributed gravity load of $20 \mathrm{kN} / \mathrm{m}$ was applied including the own weights of members.

The sections of columns and beams of the frame are shown in Table 1 .

Table 1: Sections of Columns and Beams of the frame Building

\begin{tabular}{|c||c|c|c||}
\hline Floor Level & $\boldsymbol{G}-5^{\text {th }}$ & $\boldsymbol{6}^{\text {th }}$ to $7^{\text {th }}$ & $\boldsymbol{8}^{\text {th }}$ to Roof \\
\hline \hline Columns $(\mathrm{mm})$ & $500 \times 300$ & $400 \times 300$ & $300 \times 300$ \\
\hline \hline Typical Beams $(\mathrm{mm})$ & & $400 \times 300$ \\
\hline
\end{tabular}

One selected frame (the critical one) was analyzed using STAAD PRO (2006) program. The same ground accelerations versus time periods used in seismic hazard analysis of Sudan [1] were adopted in this paper as input data to calculate the seismic response spectrum parameters, i.e., displacements and stresses. The damping ratio was taken as 0.05 (5\% of the critical damping) and typical slab thickness was $130 \mathrm{~mm}$.

Some members of the frame building were selected for the purposes of the analysis. The selected members, which are shown in Fig. (2) were:

Columns: C801, C802, C856, C857, C889 and C890.

Beams: B805, B806 and B807. 

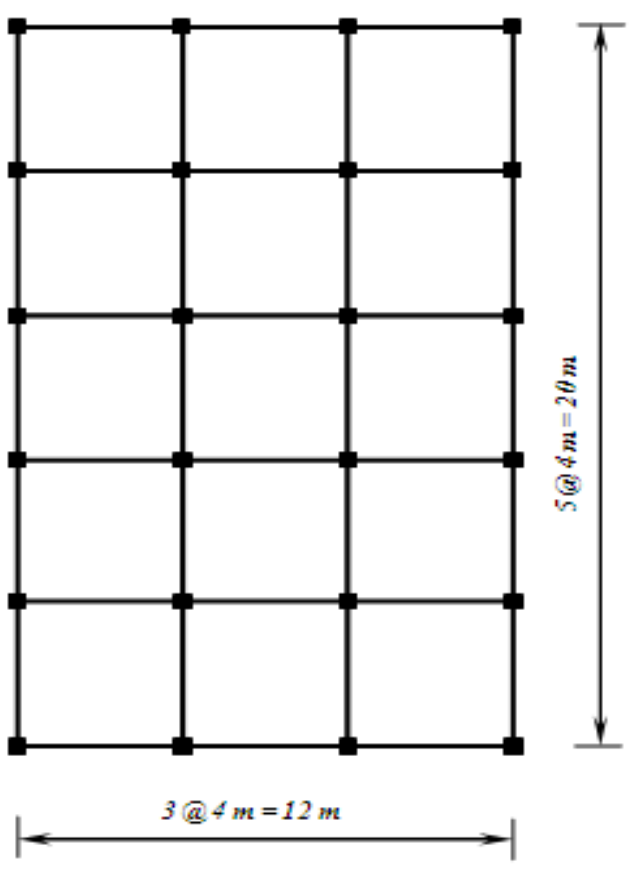

Plan

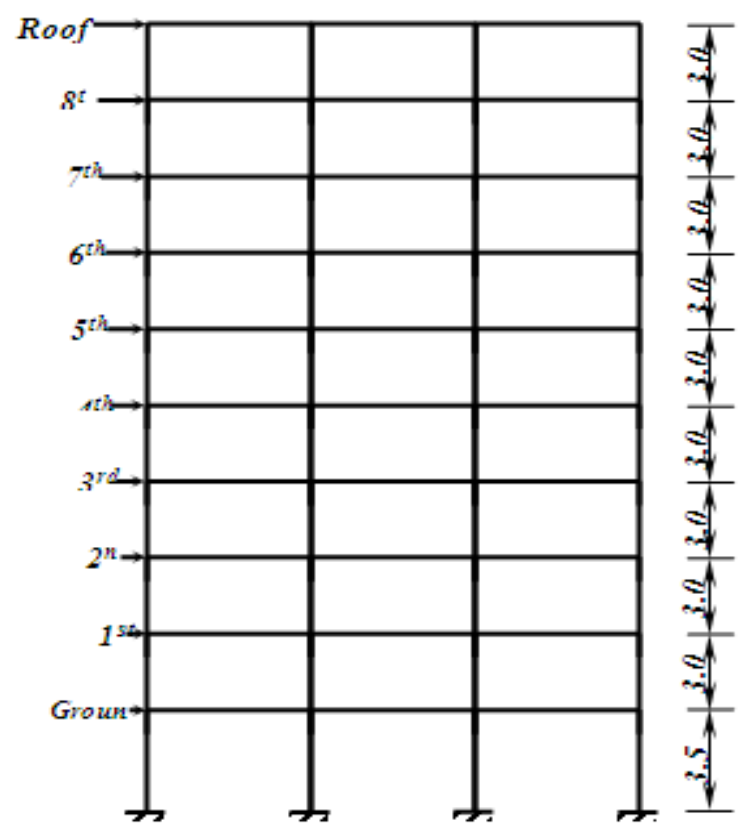

Side Elevation

Fig. 1: Dimensions of the Studied Frame Building

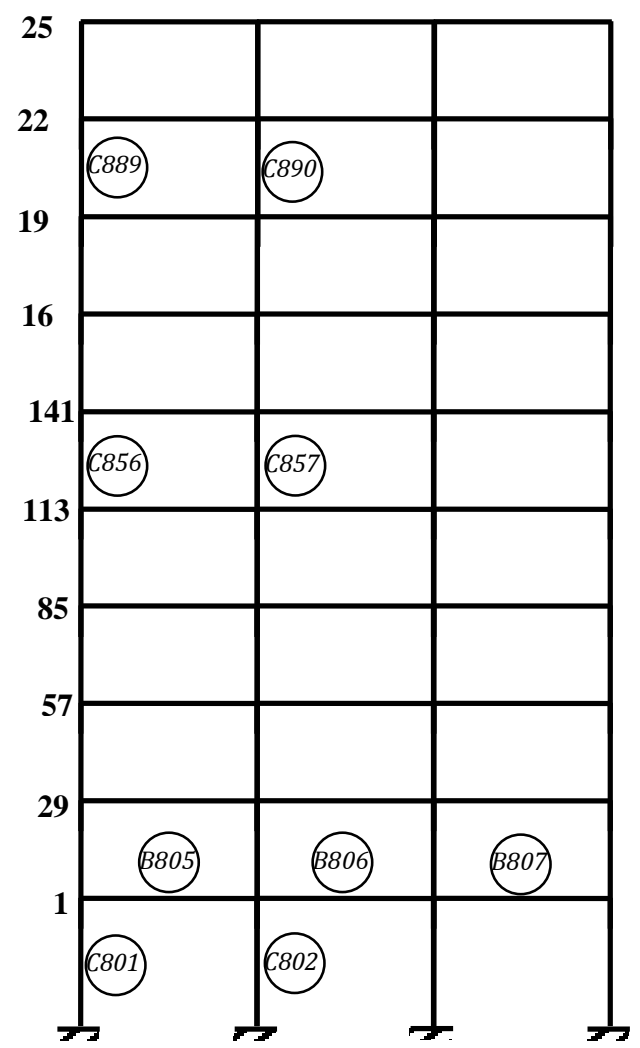

Fig. 2: Selected Nodes and Members of the Studied Frame

\section{RESULTS OF THE ANALYSIS}

The analysis was performed for static and seismic loads. The Seismic analysis used horizontal input motion of earthquake with moderate horizontal peak ground acceleration (PGAH). A total time of vibration of 8 seconds was considered. The results of the analysis are shown in Tables 2 to 7 and Figures 3 to 7 as follows: 
Table 2: Nodal Displacements of the Studied Frame

\begin{tabular}{|c|c|c|c|c|c|}
\hline Node & $L / C$ & $\begin{array}{c}\text { Horizontal } \\
X(\mathrm{~mm})\end{array}$ & $\begin{array}{l}\text { Vertical } \\
Y(\mathrm{~mm})\end{array}$ & $\begin{array}{c}\text { Horizontal } \\
\text { Z (mm) }\end{array}$ & $\begin{array}{c}\text { Resultant } \\
(\mathrm{mm})\end{array}$ \\
\hline \multirow{3}{*}{1} & 1. Dead+Live & -0.001 & $-0 . .270$ & 0.029 & 0.271 \\
\hline & 2.SeismicLoads & 20.451 & 1.381 & 0.023 & 20.498 \\
\hline & 3.Static+seismic & 20.450 & 1.111 & 0.052 & 20.480 \\
\hline \multirow{3}{*}{29} & 1. Dead+Live & -0.000 & - -0.513 & 0.118 & 0.526 \\
\hline & 2.SeismicLoads & 54.201 & 2.579 & 0.012 & 54.263 \\
\hline & 3.Static+seismic & 54.201 & 2.066 & 0.130 & 54.241 \\
\hline \multirow{3}{*}{57} & 1. Dead+Live & -0.000 & $\begin{array}{c}-0.728 \\
\end{array}$ & 0.257 & 0.772 \\
\hline & 2.SeismicLoads & 89.491 & 3.568 & 0.014 & 89.562 \\
\hline & 3.Static+seismic & 89.490 & 2.840 & 0.271 & 89.536 \\
\hline \multirow{3}{*}{85} & 1. Dead+Live & -0.000 & -0.915 & 0.441 & 1.016 \\
\hline & 2.SeismicLoads & 123.527 & 4.355 & 0.020 & 123.604 \\
\hline & 3.Static+seismic & 123.526 & 3.440 & 0.461 & 123.575 \\
\hline \multirow{3}{*}{113} & 1. Dead+Live & 0.001 & -1.073 & 0.664 & 1.262 \\
\hline & 2.SeismicLoads & 155.362 & 4.955 & 0.013 & 155.441 \\
\hline & 3.Static+seismic & 155.363 & 3.882 & 0.677 & 155.413 \\
\hline \multirow{3}{*}{141} & 1. Dead+Live & -0.001 & -1.235 & 0.926 & 1.544 \\
\hline & 2.SeismicLoads & 189.988 & 5.490 & 0.027 & 190.067 \\
\hline & 3.Static+seismic & 189.987 & 4.255 & 0.953 & 190.037 \\
\hline \multirow{3}{*}{169} & 1. Dead+Live & -0.000 & -1.362 & 1.222 & 1.830 \\
\hline & 2.SeismicLoads & 219.763 & 5.839 & 0.029 & 219.841 \\
\hline & 3.Static+seismic & 219.762 & 4.477 & 1.251 & 219.811 \\
\hline \multirow{3}{*}{197} & 1. Dead+Live & 0.002 & -1.454 & 1.546 & 2.122 \\
\hline & 2.SeismicLoads & 243.991 & 6.040 & 0.024 & 244.066 \\
\hline & 3.Static+seismic & 243.994 & 4.586 & 1.570 & 244.042 \\
\hline \multirow{3}{*}{225} & 1. Dead+Live & -0.001 & -1.532 & 1.893 & 2.436 \\
\hline & 2.SeismicLoads & 269.211 & 6.157 & 0.038 & 269.282 \\
\hline & 3.Static+seismic & 269.210 & 4.625 & 1.932 & 269.256 \\
\hline \multirow{3}{*}{253} & 1. Dead+Live & 0.004 & -1.567 & 0.037 & 2.759 \\
\hline & 2.SeismicLoads & 283.889 & 6.185 & 2.270 & 283.956 \\
\hline & 3.Static+seismic & 283.893 & 4.618 & 2.307 & 283.940 \\
\hline
\end{tabular}

Table 3: Storey Drifts in the Studied Frame

\begin{tabular}{|c|c|c|c|}
\hline Node & L/C & $\begin{array}{c}\text { Displacement } \\
\text { Resultants } \\
(\mathbf{m m})\end{array}$ & $\begin{array}{c}\text { Drift } \\
(\mathbf{m m})\end{array}$ \\
\hline 1 & Static+seismic & 20.48 & - \\
\hline 29 & Static+seismic & 54.241 & 33.761 \\
\hline 57 & Static+seismic & 89.536 & 35.295 \\
\hline 85 & Static+seismic & 123.575 & 34.039 \\
\hline 113 & Static+seismic & 155.413 & 31.838 \\
\hline 141 & Static+seismic & 190.037 & 34.624 \\
\hline 169 & Static+seismic & 219.811 & 29.774 \\
\hline 197 & Static+seismic & 244.042 & 24.231 \\
\hline 225 & Static+seismic & 269.256 & 25.214 \\
\hline 253 & Static+seismic & 283.94 & 14.684 \\
\hline
\end{tabular}


Table 4: Column End Forces of the Studied Frame

\begin{tabular}{|c|c|c|c|c|c|}
\hline Column & $L / C$ & Node & $\begin{array}{c}F x \\
(k N)\end{array}$ & $\begin{array}{c}F y \\
(k N)\end{array}$ & $\begin{array}{c}M z \\
(k N . m)\end{array}$ \\
\hline \multirow{6}{*}{$\mathrm{C} 801$} & \multirow{2}{*}{ 1. Dead+Live } & 281 & 748.451 & -7.11 & -6.94 \\
\hline & & 1 & -737.651 & 7.11 & -14.394 \\
\hline & \multirow{2}{*}{ 2.Seismic Loads } & 281 & 1726.257 & 246.283 & 591.915 \\
\hline & & 1 & -1726.26 & -246.283 & -146.98 \\
\hline & \multirow{2}{*}{ 3.Static+seismic } & 281 & 2474.708 & 239.172 & 584.976 \\
\hline & & 1 & 988.607 & 253.394 & 132.586 \\
\hline \multirow{6}{*}{ C802 } & \multirow{2}{*}{ 1. Dead+Live } & 282 & 1202.8 & -0.29 & -0.31 \\
\hline & & 2 & -1192 & 0.29 & -0.561 \\
\hline & \multirow{2}{*}{ 2.SeismicLoads } & 282 & 61.74 & 327.257 & 670.396 \\
\hline & & 2 & -61.74 & -327.257 & -311.389 \\
\hline & \multirow{2}{*}{ 3.Static+seismic } & 282 & 1264.539 & 326.967 & 670.086 \\
\hline & & 2 & -1130.26 & 327.548 & 310.828 \\
\hline \multirow{6}{*}{ C856 } & \multirow{2}{*}{ 1. Dead+Live } & 113 & 367.718 & -13.475 & -18.875 \\
\hline & & 141 & -359.078 & 13.475 & -21.55 \\
\hline & \multirow{2}{*}{ 2.Seismic Loads } & 113 & 539.066 & 150.743 & 218.587 \\
\hline & & 141 & -539.066 & -150.743 & -233.884 \\
\hline & \multirow{2}{*}{ 3.Static+seismic } & 113 & 906.784 & 137.268 & 199.712 \\
\hline & & 141 & 179.987 & 164.218 & 212.334 \\
\hline \multirow{6}{*}{ C857 } & \multirow{2}{*}{ 1. Dead+Live } & 114 & 585.068 & -3.833 & -5.408 \\
\hline & & 142 & -576.428 & 3.833 & -6.092 \\
\hline & \multirow{2}{*}{ 2.Seismic Loads } & 114 & 59.112 & 256.859 & 371.82 \\
\hline & & 142 & -59.112 & -256.859 & -398.976 \\
\hline & \multirow{2}{*}{ 3.Static+seismic } & 114 & 644.179 & 253.025 & 366.274 \\
\hline & & 142 & -517.316 & 260.692 & 392.884 \\
\hline \multirow{6}{*}{ C889 } & \multirow{2}{*}{ 1. Dead+Live } & 197 & 138.964 & -10.916 & -15.557 \\
\hline & & 225 & -132.484 & 10.916 & -17.192 \\
\hline & \multirow{2}{*}{ 2.Seismic Loads } & 197 & 90.577 & 74.298 & 103.16 \\
\hline & & 225 & -90.577 & -74.298 & -119.756 \\
\hline & \multirow{2}{*}{ 3.Static+seismic } & 197 & 229.542 & 63.381 & 87.602 \\
\hline & & 225 & -41.907 & 85.214 & 102.564 \\
\hline \multirow{6}{*}{$\mathrm{C} 890$} & \multirow{2}{*}{ 1. Dead+Live } & 198 & 236.329 & -3.157 & -4.533 \\
\hline & & 226 & -229.849 & 3.157 & -4.936 \\
\hline & \multirow{2}{*}{ 2.Seismic Loads } & 198 & 31.443 & 115.558 & 165.507 \\
\hline & & 226 & -31.443 & -115.558 & -181.171 \\
\hline & \multirow{2}{*}{ 3.Static+seismic } & 198 & 267.772 & 112.401 & 160.974 \\
\hline & & 226 & -198.406 & 118.714 & 176.234 \\
\hline
\end{tabular}

Table 5: Beam End Forces of the Studied Frame

\begin{tabular}{|c|c|c|c|c|c|}
\hline Beam & $L / C$ & Node & $\begin{array}{c}F x \\
(k N)\end{array}$ & $\begin{array}{c}F y \\
(k N)\end{array}$ & $\begin{array}{c}M z \\
(k N . m)\end{array}$ \\
\hline \multirow{6}{*}{ B805 } & \multirow{2}{*}{ 1. Dead+Live } & 1 & -3.018 & 46.253 & 30.11 \\
\hline & & 2 & 3.018 & 45.267 & -28.137 \\
\hline & \multirow{2}{*}{ 2.SeismicLoads } & 1 & 25.915 & 215.724 & 447.954 \\
\hline & & 2 & -25.915 & -215.724 & -414.941 \\
\hline & \multirow{2}{*}{ 3.Static+seismic } & 1 & 22.897 & 261.977 & 478.064 \\
\hline & & 2 & 28.933 & 260.99 & 386.804 \\
\hline \multirow{3}{*}{ B806 } & \multirow{2}{*}{ 1. Dead+Live } & 2 & -2.641 & 45.76 & 30.41 \\
\hline & & 3 & 2.641 & 45.76 & -30.41 \\
\hline & 2.SeismicLoads & 2 & 0 & 200.568 & 401.136 \\
\hline
\end{tabular}


Seismic Analysis of a Reinforced Concrete Building by Response Spectrum Method

\begin{tabular}{|c|c|c|c|c|c|} 
& & 3 & 0 & -200.568 & -401.136 \\
\cline { 2 - 6 } & \multirow{3}{*}{3. Static+seismic } & 2 & -2.641 & 246.328 & 431.546 \\
\cline { 3 - 6 } & 3 & 2.641 & 246.328 & 370.726 \\
\hline \multirow{4}{*}{ B807 } & \multirow{2}{*}{ 1. Dead+Live } & 3 & -3.018 & 45.267 & 28.137 \\
\cline { 2 - 6 } & \multirow{2}{*}{ 2.SeismicLoads } & 4 & 3.018 & 46.253 & -30.11 \\
\cline { 3 - 6 } & & 4 & -25.915 & 215.724 & 414.941 \\
\cline { 2 - 6 } & \multirow{2}{*}{3. Static+seismic } & 3 & 22.897 & -215.724 & -447.954 \\
\cline { 3 - 6 } & & 4 & 28.933 & 261.977 & 443.078 \\
\hline
\end{tabular}

Table 6: Column Stresses of the Studied Frame

\begin{tabular}{|c|c|c|c|c|c|c|}
\hline \multirow[b]{2}{*}{ Column } & \multirow[b]{2}{*}{$L / C$} & \multirow[b]{2}{*}{ Length } & \multicolumn{2}{|c|}{ Max. Compressive } & \multicolumn{2}{|c|}{ Max. Tensile } \\
\hline & & & $\begin{array}{c}\text { Stress } \\
\left(\mathrm{N} / \mathrm{mm}^{2}\right)\end{array}$ & $\begin{array}{l}\text { Dist. } \\
\text { (m) }\end{array}$ & $\begin{array}{c}\text { Stress } \\
\left(\mathrm{N} / \mathrm{mm}^{2}\right)\end{array}$ & $\begin{array}{r}\text { Dist. } \\
\text { (m) }\end{array}$ \\
\hline \multirow{3}{*}{ C801 } & 1. Dead+Live & 3 & 6.355 & 3 & & \\
\hline & 2.SeismicLoads & 3 & 59.056 & 0 & -36.039 & 0 \\
\hline & 3.Static+seismic & 3 & 63.668 & 0 & -30.671 & 0 \\
\hline \multirow{3}{*}{ C802 } & 1. Dead+Live & 3 & 8.42 & 3 & & \\
\hline & 2.SeismicLoads & 3 & 54.063 & 0 & -53.24 & 0 \\
\hline & 3.Static+seismic & 3 & 62.306 & 0 & -45.445 & 0 \\
\hline \multirow{3}{*}{ C856 } & 1. Dead+Live & 3 & 5.977 & 3 & & \\
\hline & 2.SeismicLoads & 3 & 34.229 & 3 & -33.321 & 2.75 \\
\hline & 3.Static+seismic & 3 & 33.347 & 0 & -32.355 & 2.75 \\
\hline \multirow{3}{*}{ C857 } & 1. Dead+Live & 3 & 5.768 & 0 & & \\
\hline & 2.SeismicLoads & 3 & 50.521 & 3 & -50.115 & 2.75 \\
\hline & 3.Static+seismic & 3 & 54.651 & 2.75 & -45.852 & 2.75 \\
\hline \multirow{3}{*}{ C889 } & 1. Dead+Live & 3 & 5.572 & 3 & -2.628 & 3 \\
\hline & 2.SeismicLoads & 3 & 27.97 & 3 & -27.497 & 2.75 \\
\hline & 3.Static+seismic & 3 & 30.281 & 2.75 & -29.002 & 2.75 \\
\hline \multirow{3}{*}{ C890 } & 1. Dead+Live & 3 & 3.694 & 0 & & \\
\hline & 2.SeismicLoads & 3 & 40.805 & 3 & -40.456 & 2.75 \\
\hline & 3.Static+seismic & 3 & 43.34 & 2.75 & -38.802 & 2.75 \\
\hline
\end{tabular}

Table 7: Beam Stresses of the Studied Frame

\begin{tabular}{|c|c|c|c|c|c|c|}
\hline \multirow[b]{2}{*}{ Column } & \multirow[b]{2}{*}{$L / C$} & \multirow[b]{2}{*}{ Length } & \multicolumn{2}{|c|}{ Max. Compressive } & \multicolumn{2}{|c|}{ Max. Tensile } \\
\hline & & & $\begin{array}{c}\text { Stress } \\
\left(\mathrm{N} / \mathrm{mm}^{2}\right)\end{array}$ & $\begin{array}{c}\text { Dist. } \\
(\mathrm{m})\end{array}$ & $\begin{array}{c}\text { Stress } \\
\left(\mathrm{N} / \mathrm{mm}^{2}\right)\end{array}$ & $\begin{array}{c}\text { Dist. } \\
(m)\end{array}$ \\
\hline \multirow{3}{*}{ C805 } & 1. Dead+Live & 4 & 3.747 & 0 & -3.798 & 0 \\
\hline & 2.SeismicLoads & 4 & 56.265 & 0 & -55.833 & 0 \\
\hline & 3.Static+seismic & 4 & 59.995 & 0 & -59.614 & 0 \\
\hline \multirow{3}{*}{ C806 } & 1. Dead+Live & 4 & 3.78 & 0 & -3.824 & 0 \\
\hline & 2.SeismicLoads & 4 & 50.176 & 0 & -50.176 & 0 \\
\hline & 3.Static+seismic & 4 & 53.955 & 0 & -53.999 & 0 \\
\hline \multirow{3}{*}{ C857 } & 1. Dead+Live & 4 & 3.747 & 4 & -3.798 & 4 \\
\hline & 2.SeismicLoads & 4 & 56.265 & 4 & -55.881 & 3.667 \\
\hline & 3.Static+seismic & 4 & 57.484 & 3.667 & -57.894 & 3.667 \\
\hline
\end{tabular}




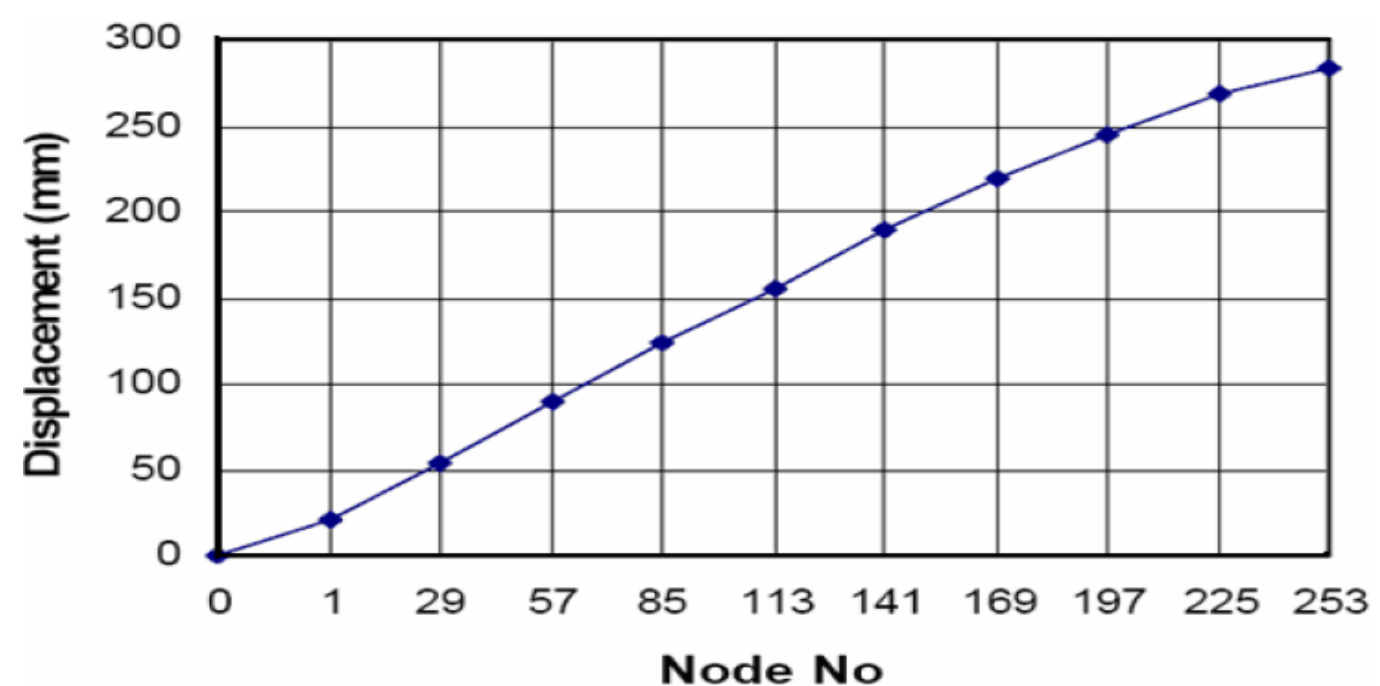

Fig. 3: Nodal Displacements of the Studied frame

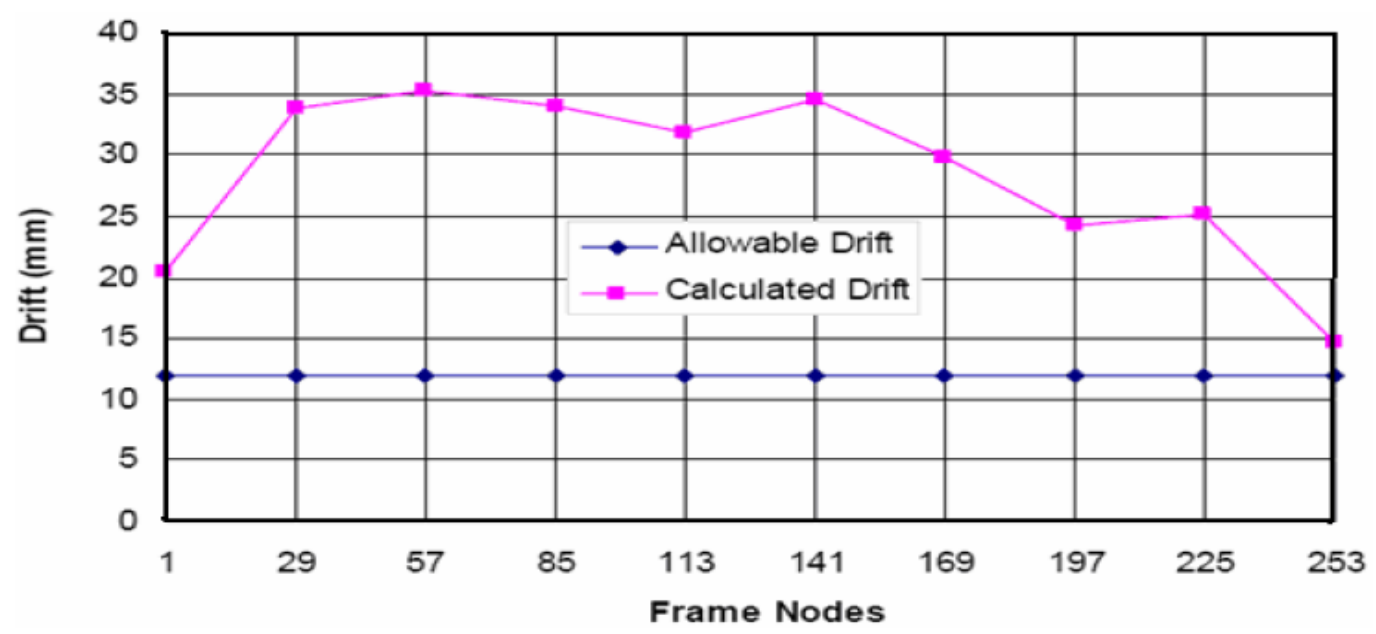

Fig. 4: Comparison between Allowable Drift and Calculated Drift of the Studied Frame

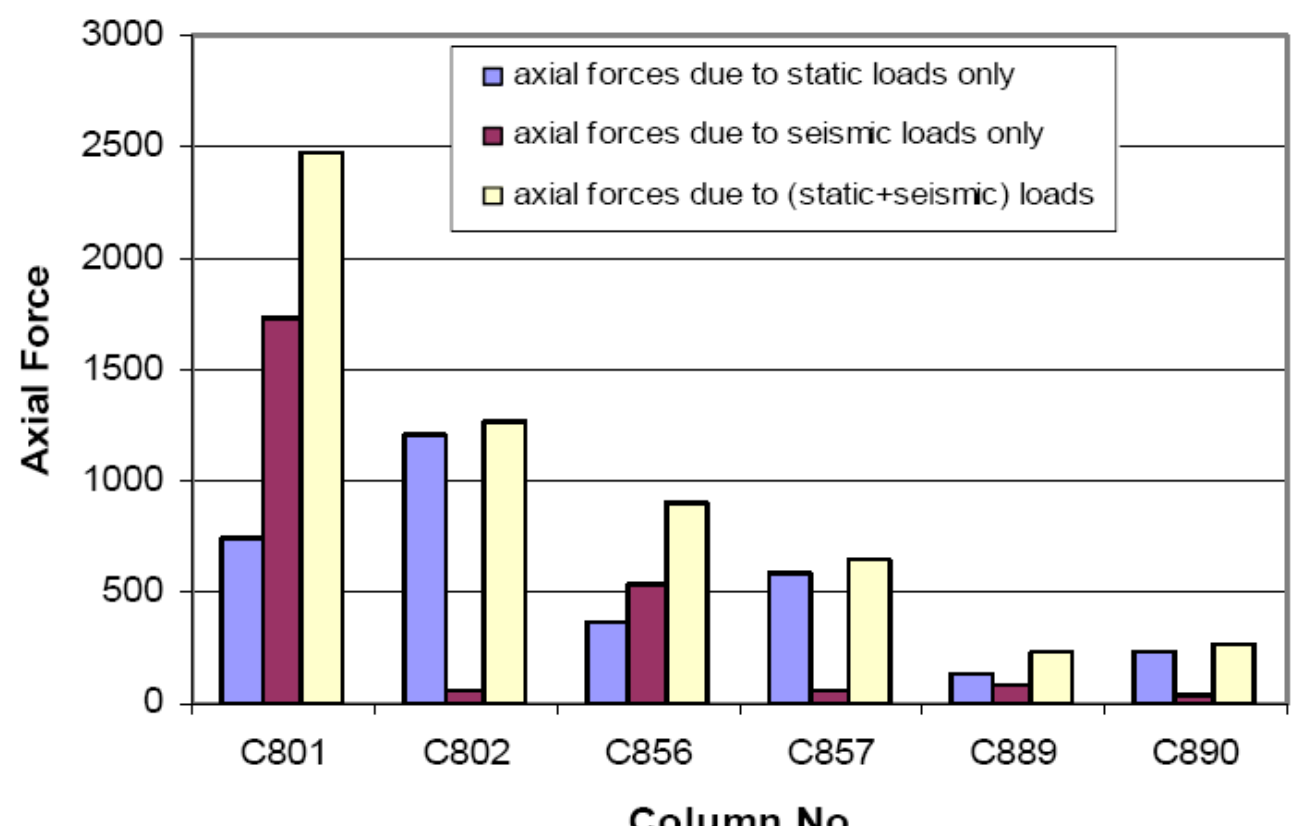

Fig. 5: Column Axial Forces of the Studied Frame 


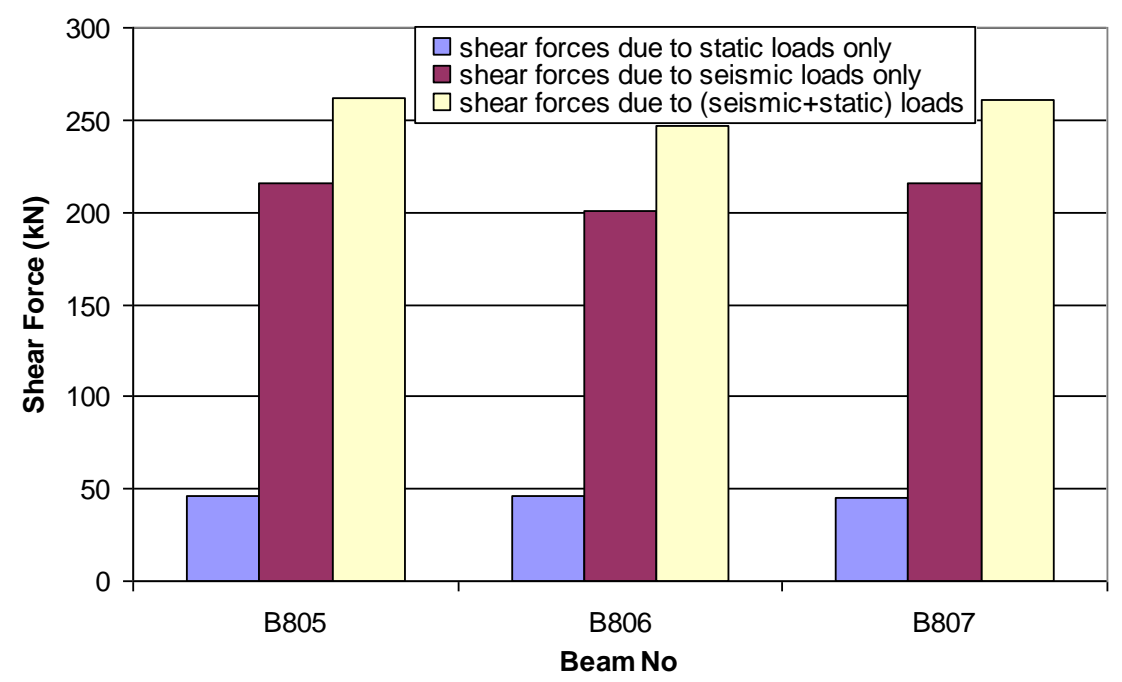

Fig. 6: Beam Shear Forces of the Studied Frame

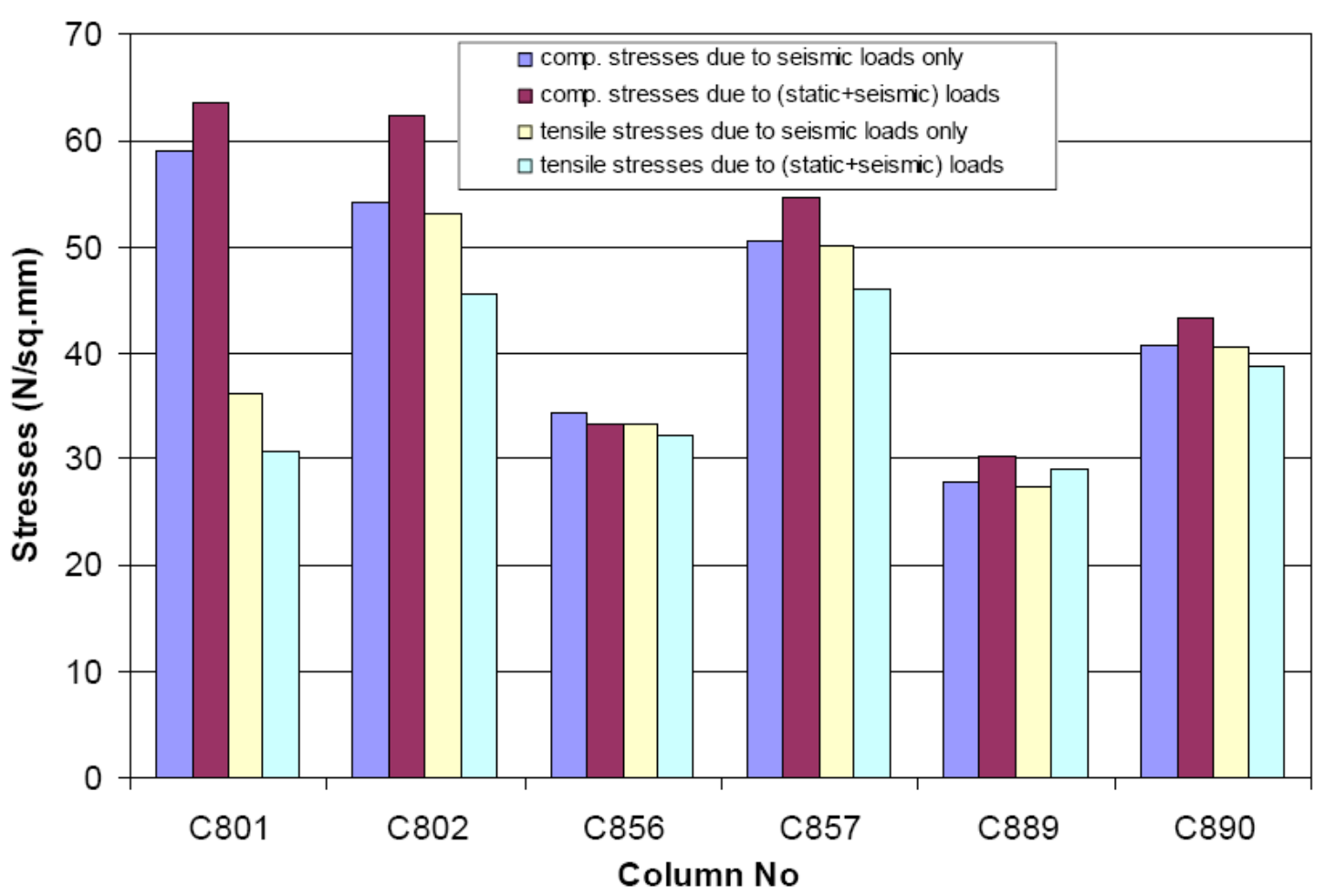

Fig. 7: Column stresses of the Studied Frame

VII. DISCUSSIONS OF THE ANALYSIS RESULTS

The results of the analysis indicated that the frame suffered a maximum horizontal displacement of $28.39 \mathrm{~cm}$ at its top level as shown in Table 2 and graphically in Fig. 3. This represents about $0.94 \%$ of the frame total height. These nodal displacements caused drifts in excess of the allowable drifts. Table 3 shows that the drift reached up to $35 \mathrm{~mm}$ in some levels while the allowable drift in this frame should not be greater than 0.004 times the story height $(12 \mathrm{~mm})$ [ ]. In other words, the calculated drifts of the frame were about 2 to 3 times the allowable drifts as shown graphically in Fig. 4.

Axial forces, shear forces and bending moments increased in columns and beams due to seismic excitation. It can be observed that the axial force due to L/C3 increased in the exterior column C801 while the interior column C802 had an opposite variation trend, its axial forces due to $\mathrm{L} / \mathrm{C} 1$ is greater than that of $\mathrm{C} 801$, whereas its axial force due to $\mathrm{L} / \mathrm{C} 3$ is lesser than that of $\mathrm{C} 801$. However, the forces in upper floor columns showed lesser values as shown in Table 4 and Fig. 5. These values indicated that horizontal motion has a greater 
effect on the axial compression loads of the exterior columns compared to the interior columns because of the overturning moment effect.

Shear forces due to the combined effect of static and seismic loads in interior columns are greater than those in exterior columns and decreased in the upper levels as in Table 4 . The values of shear forces due to $\mathrm{L} / \mathrm{C} 3$ in beams B805, B806 and B807 were found to be about four times the values due to $\mathrm{L} / \mathrm{C} 1$ as in Table 5 and Fig. 6. These large increases of compression and shear forces can lead to compression shear failure especially if accompanied with poor detailing [7].

Table 6 and Fig. 7 show that seismic excitations caused maximum compressive stresses at the bottom of C801 and C802. In other columns, these stresses occurred at different distances along the columns. It is also observed that there were no tensile stresses displayed due to L/C1. Tensile stresses in C801 and C802, generated by seismic excitation, occurred at their bottom levels. In general, compressive stresses in columns showed greater values than tensile stresses. Table 7 shows that the maximum values of compressive and tensile stresses in beams are approximately equal. These stresses mainly occurred at the end of the beams.

\section{CONCLUSIONS}

Based on the obtained results from the analysis of the reinforced concrete frame building in Khartoum city, it can be concluded that:

1. The interior columns in all floor levels were the most affected by the compression forces resulting from all cases of load combinations.

2. Bending moments in beams and columns due to seismic excitation showed much larger values compared to that due to static loads.

3. The compressive stresses generated from all cases of loads in ground floor columns were greater than tensile stresses in these columns whereas in other levels the difference was slight. The compressive stresses in ground floor columns were about 1.2 to 2 times the tensile stresses.

4. Compressive and tensile stresses in the studied beams were approximately equal.

5. The calculated drifts resulting from the nodal displacements due to the combination of static and seismic loads were about 2 to 3 times the allowable drifts.

6. The frame was inadequate to resist the applied seismic load.

\section{REFERENCES}

[1] A.E. Hassaballa, Probabilistic Seismic Hazard Assessment and Seismic Design Provisions for Sudan, Ph.D. Thesis, SUST, 2010.

[2] Mario Paz, and William Leigh, Dynamics of Structures (fifth edition, Textbook of Kluwer Academic Publishers), 2004.

[3] Uma, S.R., and Jain, S. K., Seismic Design of Beam-Column Joints in RC Moment Resisting FramesReview of Codes, structural Engineering and Mechanics, Vol. (23), No. (5), 2006, PP. 579 - 597.

[4] S.S. Patil, S.A. Ghadge , C.G. Konapure, Mrs.C.A. Ghadge,Seismic Analysis of High-Rise Building by Response Spectrum Method, International Journal of Computational Engineering Research (Ijceronline.Com), Vol. (3) Issue. (3), March 2013, PP. 272 - 279.

[5] STAADPRO, Version 8i, Research Engineers International, by Bentley Systems, 2007.

[6] BS 8110. (1997),the Structural Use of Concrete, British Standard Institution, London.

[7] Guido MAGENES and Stefano PAMPANIN, Seismic Response of Gravity-Load Design Frames with Masonry Infills, 13th World Conference on Earthquake Engineering, Vancouver, B.C., Canada, August 1-6, 2004, Paper No. 4004. 